\title{
Access to free health-care services for the poor in tertiary hospitals of western Nepal: a descriptive study
}

\author{
Preeti K Mahato ${ }^{1}$, Giridhari Sharma Paudel ${ }^{2}$
}

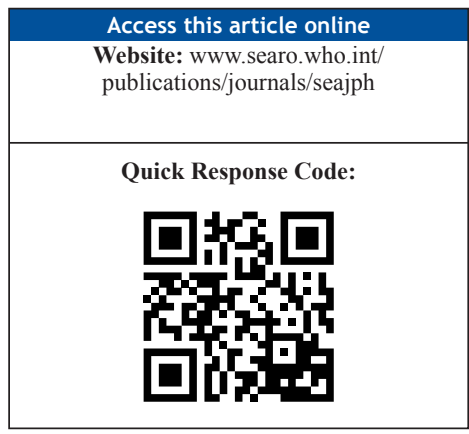

\begin{abstract}
Background: Nepal is an underdeveloped country in which half of the total health expenditure is from out-of-pocket payments. Thus, the Government of Nepal introduced universal free health-care services up to the level of district hospitals, and targeted these services to poor and marginalized people in regional and subregional hospitals. The aim of this descriptive study was to explore the implementation and utilization of free health-care services by the target population (poor and marginalized people) in two tertiary-care hospitals in western Nepal, one with a social care unit (Western Regional Hospital) and one without a social care unit (Lumbini Zonal Hospital).
\end{abstract}

Methods: Medical records maintained by the two hospitals for one Nepali calendar year were collected and analysed, along with information from key informant interviews with staff from each hospital and patient exit interviews.

Results: Utilization of free health-care services by poor and marginalized people in the two tertiary-care hospitals was suboptimal: only $8.4 \%$ of patients using services were exempted from payment in Western Regional Hospital, whereas it was even fewer, at $2.7 \%$, in Lumbini Zonal Hospital. There was also unintended use of services by nontarget people. Qualitative analysis indicated a lack of awareness of free health-care services among clients, and lack of awareness regarding target groups among staff at the hospitals. Importantly, many services were utilized by people from rural areas adjoining the district in which the hospital was situated.

Conclusion: Utilization of free health-care services by the target population in the two tertiary-care hospitals was very low. This was the result of poor dissemination of information about the free health-care programme by the hospitals to the target population, and also a lack of knowledge regarding free services and target groups among staff working in these hospitals. Thus, it is imperative to implement educational programmes for hospital staff and for poor and marginalized people. Unintended use of free services was also seen by nontarget groups; this suggests that there should further simplification of the process to identify target groups.

Key words: free health care, out-of-pocket expenditure, social service unit, target group, tertiary health care
${ }^{1}$ Faculty of Health and Social Sciences, Bournemouth University, Bournemouth, United Kingdom of Great Britain and Northern Ireland, ${ }^{2}$ United Nations Development Programme/National Planning Commission, Kathmandu, Nepal

Address for correspondence: Dr Giridhari Sharma Paudel, Monitoring and Evaluation Specialist, United Nations Development Programme/National Planning Commission, Singha Durbar, Kathmandu, Nepal Email: giridharisp@gmail.com

\section{BACKGROUND}

The 1978 Declaration of Alma-Ata, expressing an urgent need for health for all by 2000 , established that health is a fundamental human right and that the attainment of the highest possible level of health is a most important worldwide social goal, with action required from health-care sectors as well as social and economic sectors. ${ }^{1}$ Despite this, there is evidence of a widening gap in access to basic health-care services in resource-poor countries 30 years after the Declaration of AlmaAta. ${ }^{2}$ In low-income countries, most of the domestic healthcare expenditure is out-of-pocket (OOP) payment, rather than prepaid insurance. In addition, the proportion of spending from public budgets is low. ${ }^{3}$ In low-income countries, direct OOP payments prevent many people from seeking care, resulting in catastrophic health spending. ${ }^{4}$ In Asia, households with higher income contribute more to health-care financing, and the more affluent families spend more in OOP expenses in low-income 
and middle-income Asian countries. ${ }^{5}$ In Nepal, the main source of health-care financing is OOP payment, which accounts for more than half of the total health expenditure in the country. 5,6

Universal health coverage aims to ensure that all people have access to the services they need without the risk of financial ruin. ${ }^{7,8}$ Establishment of universal health coverage requires systems that raise the bulk of funds through prepayment methods (for example, taxes and/or insurance), and then pool these funds to spread the financial risk of illness across the population. ${ }^{9}$ The state of health-care financing in Nepal is weak, as over $60 \%$ of the population lacks quality access to basic essential care such as maternity services. ${ }^{6}$ In addition to this, high reliance on OOP payments means that health care has a high catastrophic share of household spending, and this can lead to impoverishment or nonaccess by patients, as it is the most inequitable form of health-care financing. ${ }^{10}$

The mandate of The Interim Constitution of Nepal 2063 (2007) emphasized that every citizen shall have the right to basic health-care services free of cost, as provided by law. ${ }^{11}$ As a result, the Government of Nepal has provided essential healthcare services free of charge in district hospitals, primary healthcare centres, health posts and subhealth posts, to all people. ${ }^{12}$ The free health-care policy covers consultation and treatment, minor surgery, obstetric emergencies, basic and comprehensive obstetric care, radiographs, laboratory services, essential drugs (for a week) and transport by ambulance to a higher-level facility when a patient is referred. ${ }^{13}$ As a result of this free health-care initiative, health-care access is steadily expanding; however, critical gaps still persist, and additional resources for health are required. ${ }^{6}$ Patients in tertiary-care health facilities are still required to pay for services. ${ }^{14}$

In order to increase the access to universal health-care services in tertiary-level hospitals for poor and marginalized people who have no ability to pay, the Ministry of Health and Population in Nepal has officially defined six target groups for free healthcare services: poor (able to earn enough for adequate food for 6 months to fewer than 12 months in a year), ultrapoor (able to earn enough for adequate food for less than 6 months in a year), helpless/destitute, disabled, senior citizens aged 60 years or older, and female community health volunteers (FCHVs); these groups are entitled to free health-care services in tertiarylevel hospitals. ${ }^{15}$

Some studies have evaluated the implementation of the free health-care policy in health posts and subhealth posts, and in hospitals up to district level; however, there is limited information available on the effectiveness of this policy for access to the health-care system, especially for the marginalized and poor ${ }^{15-17} \mathrm{~A}$ study conducted in a regional hospital in the midwestern region of Nepal attempted to evaluate the situation regarding financial protection for patients and access to free services available at that facility. ${ }^{17}$ However, there is no such evidence available for the tertiary-level hospitals of the western region of Nepal. Therefore, the aim of this study was to assess the access to, and the state of, free heath-care services for the target population in two tertiary-level hospitals in western Nepal.

\section{METHODS}

\section{Selection of tertiary-level hospitals for data collection}

Two tertiary-level public hospitals, Western Regional Hospital (WRH) located in Pokhara in Kaski district, and Lumbini Zonal Hospital (LZH) located in Butwal in Rupandehi district, were selected for this study, as being representative of referral hospitals in Nepal, based on their patient flow and number of referred patients from peripheral districts. The tertiary-level hospitals selected for this study are defined as referral hospitals that have specialized curative services, and patients are referred from community and district hospitals for specialized services. These two hospitals were chosen from the three public-funded tertiary hospitals in the western region of Nepal because of their very large patient flow and also because they have a budgetary allocation to provide free health care to the target population. The third public tertiary hospital in the region, Dhaulagiri Zonal Hospital, was not selected because it had been upgraded from a district hospital 1 year before the start of the study and was still in the early stages of generating referral-level service data at the time of this study.

The total number of available beds in WRH at the time of the study was 325 out of 500 sanctioned, owing to limited staff and hospital management. There was a high bed-occupancy rate of $71 \%$ and the hospital served mostly poor people from Kaski district and patients referred from surrounding district hospitals, such as those in Syangja, Manang, Tanahun, Gorkha and Lamjung. The total number of patients treated by WRH in the year of the study was 216007 . LZH, on the other hand, had 135 beds out of 200 sanctioned, with a high bed-occupancy rate of $82 \%$ and it mostly served poor people from Rupandehi district and patients referred from surrounding district hospitals, such as those in Gulmi, Arghakhanchi, Kapilvastu, Palpa and Nawalparasi, and those from peripheral facilities in the southern part of Syangja. The total number of hospital services provided by LZH in the study year was 177817 , which was less than the number provided by WRH. ${ }^{18,19}$ In addition to the public tertiary hospitals, there are two private teaching hospitals in Pokhara, Kaski district, with a total of 1125 beds. There is also one private teaching hospital and one medical college in Rupandehi district with 1020 beds altogether, and one private teaching hospital in Palpa district with 300 beds. Therefore, there are more tertiary hospitals in the vicinity of LZH than in the vicinity of WRH. Poor and marginalized people cannot afford to pay the service fees for private hospitals, and therefore they prefer to use public hospitals. However, those who can afford to pay the high fees prefer to attend private medical facilities. ${ }^{19}$

The Ministry of Health and Population (MoHP) in Nepal has been piloting the establishment of social service units (SSUs) in eight hospitals. The role of the SSU is to facilitate identification of target groups and enable free and partially free health-care service delivery to these populations. ${ }^{20}$ The two hospitals selected for the present study differed in that an SSU was established in WRH in 2012, whereas there is no such unit in LZH. 


\section{Data collection method}

One Nepali calendar year, 2069 (2011-2012), was chosen for information collection for this study. This year was selected based on the availability of records on free health-service provision for the target population in the chosen hospitals. There was no systematic record-keeping system for each individual patient on free health-care service provision prior to this year. Information on the patients who received free healthcare services from the two selected hospitals was collected monthly, from Baishak (April) 2069 (2011) to Chaitra (March) 2069 (2012), for analysis.

Microsoft Excel software was used to produce a spreadsheet for data collection from the record registers of the two hospitals. The following information on each patient was collected for 1 year: name, age, sex, address (by district and village development committee (VDC), place of residence (urban or rural), target group (poor, ultrapoor, helpless/destitute, disabled, senior citizen or FCHV), marital status, ethnicity (as specified by the Health Management Information System: group 1, dalit; group 2, disadvantaged janajati; group 3, disadvantaged non-dalit; group 4, religious minority; group 5, relatively disadvantaged janajati; group 6, upper caste), types of health care received, and the name of the department where the patient accessed free health-care services. A data-collection team comprising four enumerators and a supervisor was formed at the Western Regional Health Directorate (WRHD), and this team visited both hospitals and collected patient information from the records.

\section{Key informant and client interviews}

A brief closed-ended interview questionnaire for the key informant interview was developed at WRHD and pretested at WRH. The questionnaire was revised based on pretest feedback, and a final version was produced. A total of six key informants, including a medical doctor, a matron, an official and a facilitator working in the SSU and a medical recorder, were interviewed at WRH, whereas a total of six key informants, including a medical doctor, a matron and paramedics, were interviewed at LZH. The following information was collected from the key informants: identification of target groups, facilitation processes within the hospital to access free health-care services by target groups, and problems faced by the hospital in delivery of free health-care services to target groups.

Similar to the key informant interviews, a brief close-ended interview checklist was developed, pretested and finalized for patient exit interviews. A total of 12 patients were interviewed, and information was collected on how they were able to reach the hospital, their satisfaction with the free services, how they obtained free health-care services, and what types of problems they had encountered to get the free health-care services.

The selection of participants was purposive, based on the amount of information that could be obtained from them. Face-to-face interviews were conducted by the supervisor in a quiet area within the hospital premises, where nobody could overhear the conversation.

\section{Ethical issues}

Ethical issues relating to this study, including data collection, analysis and interpretation, and the analysis report prepared by the research team, were approved by the research committee at WRHD. Informed consent for data collection and analysis was obtained from the medical superintendent of each hospital. Similarly, verbal consent was obtained before the interviews of key informants and exit patients. Confidentiality of the individuals and the information was maintained and the data provided were used only for the purposes of this study.

\section{Data analysis}

The secondary data collected from the hospital record registers were entered into the Excel spreadsheet. This was then imported to Statistical Package for Social Sciences (SPSS) software for quantitative analysis. Frequency tables required for analysis were then generated. The qualitative data collected through interview with key informants and patient exit surveys were analysed using Epi Info qualitative data analysis software, by counting the frequency of responses.

\section{RESULTS}

\section{Free health-care services in Western Regional Hospital}

Patient flow in WRH was relatively high. A total of 194553 patients visited WRH for health care in the survey year (see Table 1). The average monthly flow of patients was 16212 , and the daily patient flow was 746 persons (assuming 261 working days for the hospital). Of the total number of patients, $16417(8.4 \%)$ received free health-care services, and hence the average flow of patients from the target groups was 1368 per month and 63 per day. The numbers of male $(8116,49.4 \%)$ and female $(8301,50.6 \%)$ patients were approximately equal. The geographical distribution showed that free health-cae service utilization was highest in those from Kaski district $(51.8 \%)$, where the hospital is located, while the remaining $48.2 \%$ of patients were from 57 peripheral districts. The poor $(78.8 \%)$ and senior citizens $(10.5 \%)$ were the two highest users of the service in the target groups. For the ethnic group analysis, patients from group 6, upper caste, utilized most free services $(39.8 \%)$; those from group 1 , which consists of the relatively poor dalit (lower caste) group, were the next highest users of free services (34.4\%). The rural-urban distribution of patients using free services at WRH showed that most of the free services intended for the disadvantaged and poor were used by those living in rural areas (66.4\%), and only $33.6 \%$ of free services were used by people living in urban areas.

The age group distribution, according to the hospital department in which the patients sought free services, showed that the highest number belonged to the age group 41-60 years in the general medicine department for free medicines (1961 patients), whereas the highest number belonged to the age group 21-40 years in the general medicine department for free investigations group (626 patients) (see Table 2). 


\begin{tabular}{|c|c|c|c|}
\hline Characteristic & $\begin{array}{c}\text { Patients accessing free } \\
\text { services, } n(\%)\end{array}$ & Male, $n(\%)$ & Female, $n(\%)$ \\
\hline Total number of patients: 194553 & $16417(8.4)$ & $8116(49.4)$ & $8301(50.6)$ \\
\hline \multicolumn{4}{|l|}{ Rural-urban distribution } \\
\hline Urban & $5506(33.6)$ & $2702(49.0)$ & $2804(51.0)$ \\
\hline \multicolumn{4}{|l|}{ Geographical distribution } \\
\hline Kaski district & $8516(51.8)$ & - & - \\
\hline \multicolumn{4}{|l|}{ Target group } \\
\hline Ultrapoor & $1003(6.1)$ & $437(43.5)$ & $566(56.5)$ \\
\hline Helpless & $350(2.1)$ & $160(45.7)$ & $190(54.3)$ \\
\hline Senior citizen & $1711(10.5)$ & $762(44.5)$ & $949(55.5)$ \\
\hline Female community health volunteer & $31(0.1)$ & $2(6.4)$ & $29(93.6)$ \\
\hline Disabled & $401(2.4)$ & $186(46.3)$ & $401(53.7)$ \\
\hline \multicolumn{4}{|l|}{ HMIS ethnic group } \\
\hline Group 1: dalit & $5655(34.4)$ & $2828(50.0)$ & $2827(50.0)$ \\
\hline
\end{tabular}

HMIS: Health Management Information System.

Source: compiled from the hospital record register available at Western Regional Hospital.

\section{Free health-care services in Lumbini Zonal Hospital}

The average patient flow per day was 500 in LZH. An average of 13 patients received free health-care services per clinic day. During the study period, a total of 3506 patients received free health-care services; this accounts for $2.7 \%$ of the total number of patients attending the hospital during the same period (130 398). The number of males using the free service was 1827 (52.1\%). The geographical distribution of free health consultation in LZH showed that those from the home district (that is, Rupandehi district) accounted for $56.4 \%$, and the remaining $43.6 \%$ were from 21 peripheral districts. The target group distribution of patients receiving free health care showed that most free service consultations were made by senior citizens $(82.4 \%)$, followed by the poor $(12.3 \%)$. Similar to $\mathrm{WRH}$, the free service users by ethnic group showed that most of the services were utilized by group 6 , upper caste $(52.5 \%)$, followed by group 1, the dalit (lower caste) group (19.4\%). The urban-rural distribution of the free-service patients at $\mathrm{LZH}$ showed that most of the free services intended for the disadvantaged and poor community were used by those living in urban areas $(64.4 \%)$ rather than those living in rural areas $(35.6 \%)$ (see Table 3$)$.

The age group distribution according to the hospital department in which the patients sought free service showed that the highest number of patients were those over 60 years, for both free medicines and free investigations. In addition, the general medicine department was most utilized for both free medicines 


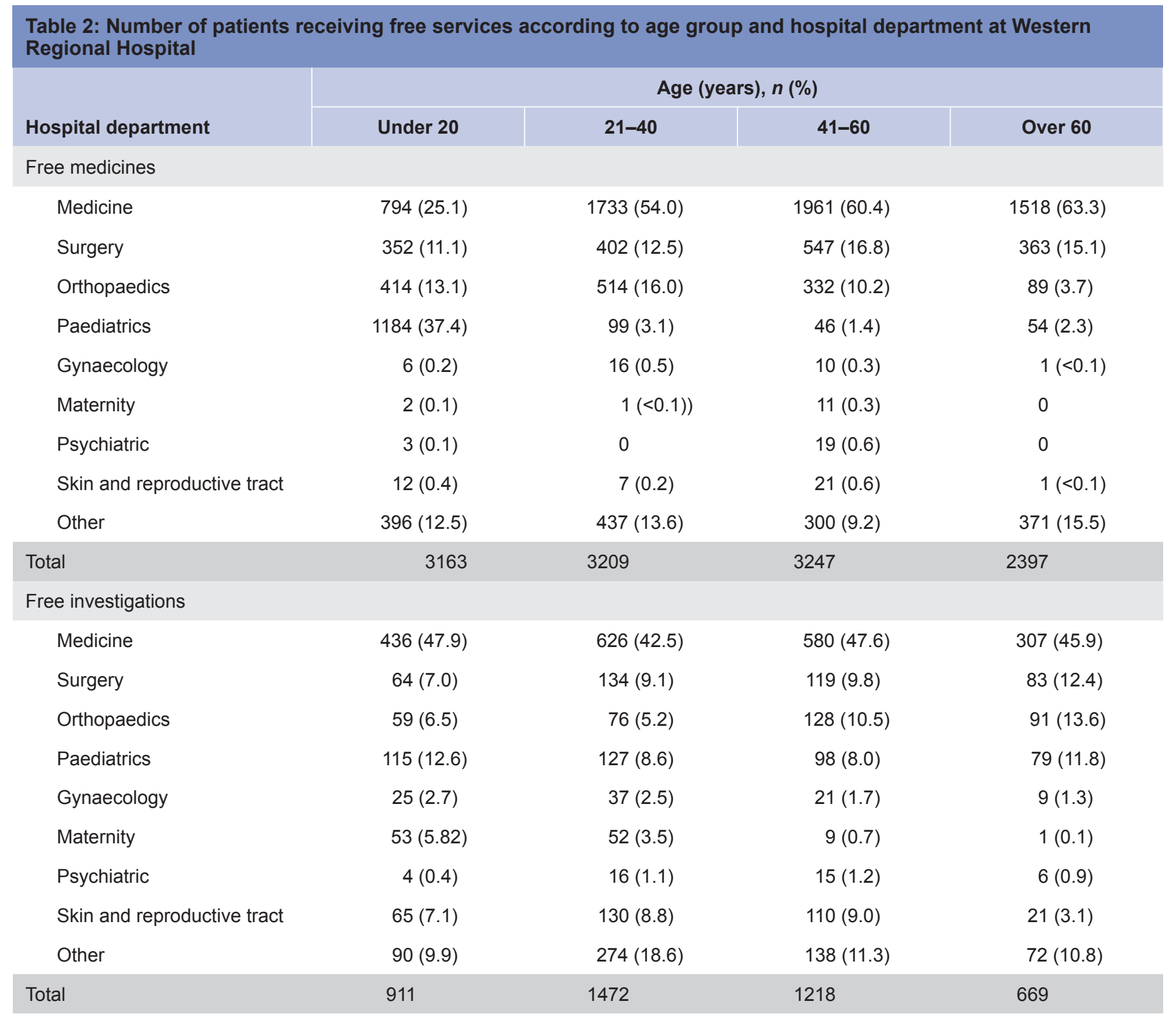

Source: compiled from the hospital record register available at Western Regional Hospital.

and free investigations. The number of free-service patients in the over-60 age group was 596 in the free medicine group, and 1381 for the same age group in the free investigation group (see Table 4).

\section{Views of key informants on provision of free health-care services}

Six health-care service providers from WRH and six from $\mathrm{LZH}$ were interviewed regarding their viewpoint on free health-care services. Knowledge of the six target groups was relatively lacking among the health-care providers and not one provider could identify all six target groups. All 12 health-care providers admitted that they provided free services and all answered that the way to identify target groups was by asking patients their status; seven of 12 also said it was by looking at their outfit, while all six key informants at WRH said it was by looking at the referral slip from the SSU, and five of 12 said it was by looking at the recommendation letter from the VDC. Eight of $12 \mathrm{key}$ informants linked the difficulty they faced in providing free services to the difficulty in identifying target groups. While all 12 key informants thought that the free health-care service was effective and 10 expressed their satisfaction in providing the free services, some still thought that there were some weaknesses in the system: eight thought it was due to poor awareness among all target groups regarding the availability of free services. This was highlighted again in their response to ways in which to improve free services: seven of 12 said the process of identifying target groups should be 


\begin{tabular}{|c|c|c|c|}
\hline Characteristic & $\begin{array}{l}\text { Patients accessing } \\
\text { free services, } n(\%)\end{array}$ & Male, $n(\%)$ & Female, $n(\%)$ \\
\hline Total number of patients: 130398 & $3506(2.7)$ & $1827(52.1)$ & 1679 (47.9) \\
\hline \multicolumn{4}{|l|}{ Rural-urban distribution } \\
\hline Rural & $1247(35.6)$ & $681(54.6)$ & $566(45.4)$ \\
\hline Urban & $2259(64.4)$ & $1146(50.7)$ & $1113(49.3)$ \\
\hline \multicolumn{4}{|l|}{ Geographical distribution } \\
\hline Rupandehi district & $1976(56.4)$ & - & - \\
\hline Other district & $1529(43.6)$ & - & - \\
\hline \multicolumn{4}{|l|}{ Target group } \\
\hline Poor & $425(12.3)$ & $235(54.8)$ & $190(45.2)$ \\
\hline Ultrapoor & $131(3.8)$ & $57(43.5)$ & $74(56.5)$ \\
\hline Helpless & $44(1.4)$ & $18(40.9)$ & $26(39.1)$ \\
\hline Senior citizen & $2884(82.4)$ & $1500(52.0)$ & $1384(48.0)$ \\
\hline Female community health volunteer & $1(<0.1)$ & 0 & $1(<0.1)$ \\
\hline Disabled & $2(<0.1)$ & $1(<0.1)$ & $1(<0.1)$ \\
\hline \multicolumn{4}{|l|}{ HMIS ethnic group } \\
\hline Group 1: dalit & $681(19.4)$ & $326(47.8)$ & $355(52.2)$ \\
\hline Group 2: disadvantaged janajati & $491(14.0)$ & $247(50.3)$ & $244(49.6)$ \\
\hline Group 3: disadvantaged non-dalit & $184(5.2)$ & $81(44.0)$ & $103(56.0)$ \\
\hline Group 4: religious minority & $56(1.6)$ & $34(60.7)$ & $22(39.3)$ \\
\hline Group 5: relatively disadvantaged janajati & $255(7.3)$ & $146(57.2)$ & $109(42.8)$ \\
\hline Group 6: upper caste & $1839(52.5)$ & $993(54.0)$ & $846(46.0)$ \\
\hline
\end{tabular}

HMIS: Health Management Information System.

Source: compiled from the hospital record register available at Lumbini Zonal Hospital.

made more effective and easy. Similarly, six informants also said that there should be easy availability of free medicines, services and positioning of appropriate human resources (quantity and quality).

\section{Patients' satisfaction with free health-care services}

Twelve patients, six from WRH and six from LZH, among those who came to use the free health-care services were selected for the patient exit survey. There were mixed views regarding the ease of availability of free services: six of the 12 thought the services were readily available and the remaining half thought that they were not readily available. The fact that there were seven patients who received information about free services from the health-care providers after attending the hospital indicated that there was not adequate knowledge regarding free services among the target population, and this was preventing them from actively seeking these services. While eight patients in the survey were satisfied with the free services, and seven did not feel that they had any difficulty while utilizing the services, all 12 expressed that there was a need to increase awareness regarding the free services among the target groups.

\section{Performance of SSUs}

As stated in Social Service Unit Establishment and Operational Guidelines, $2069(2012)^{20}$ of MoHP, a separate office space is allocated for the SSU in WRH, with same hours of operation 


\begin{tabular}{|c|c|c|c|c|}
\hline \multirow[b]{2}{*}{ Hospital department } & \multicolumn{4}{|c|}{ Age (years), $n(\%)$} \\
\hline & Under 20 & 21-40 & $41-60$ & Over 60 \\
\hline \multicolumn{5}{|l|}{ Free medicines } \\
\hline Surgery & $2(4.8)$ & $4(3.2)$ & 0 & $66(6.0)$ \\
\hline Orthopaedics & $2(4.8)$ & $11(8.9)$ & $10(13.9)$ & $165(14.9)$ \\
\hline Paediatrics & $7(16.7)$ & 0 & 0 & $2(0.2)$ \\
\hline Gynaecology & 0 & $11(8.9)$ & $1(1.3)$ & $12(1.09)$ \\
\hline Skin and reproductive tract & $4(9.5)$ & $19(15.4)$ & $9(12.5$ & $80(7.2)$ \\
\hline Other & $7(16.7)$ & $25(20.3)$ & $20(27.8)$ & $175(15.8)$ \\
\hline Total & 42 & 123 & 72 & 1104 \\
\hline \multicolumn{5}{|l|}{ Free investigations } \\
\hline Medicine & $24(42.9)$ & $105(71.4)$ & $59(67.0)$ & $1381(72.4)$ \\
\hline Surgery & $6(10.7)$ & $8(5.4)$ & $4(4.5)$ & $105(5.5)$ \\
\hline Orthopaedics & $2(3.6)$ & $7(4.8)$ & $10(11.4)$ & $162(8.5)$ \\
\hline Total & 56 & 147 & 88 & 1907 \\
\hline
\end{tabular}

Source: compiled from the hospital record register available at Lumbini Zonal Hospital.

as the hospital. Patients who know of the SSU go straight to the front desk at the SSU. Those who fall into the target groups but do not know about the SSU go first to the outpatient department (OPD) and are taken to the SSU by support staff of the respective OPD section. SSU unit staff then identify patients belonging to the target groups and provide them with a slip for free treatment. The clients then go to the appropriate OPD or inpatient department, as directed by SSU staff, with the treatment slip for a check-up and treatment. The SSU in WRH has two administrative staff: one unit chief and one facilitator working from 10:00 to 17:00. This unit is equipped with a computer and information is recorded on software generated for SSUs by the government. The identification of target groups was based on criteria as outlined by the SSU guidelines. The SSU in WRH has been operating according to Social Service Unit establishment and operational guidelines 2069 (2012). ${ }^{20}$ All those who came to the hospital and who met the criteria for inclusion in the target groups were provided with free services. However, the patient exit survey indicated that six patients, three of whom attended WRH, did not feel that the free services were readily available. Also, the patient exit survey showed that SSU staff members were not readily available to facilitate free services for the target population; therefore, it is essential that SSU staff are available at all times.

Unlike WRH, there is no SSU at LZH. Patients entitled to free care were identified by those who were involved in patient care and treatment, and the identification was usually based on the second criterion mentioned in the Social Service Unit establishment and operational guidelines 2069 (2012) (that is, by looking at the appearance and outfit of the patient). ${ }^{20} \mathrm{In}$ some instances, poor people brought an identification document from their VDC, which was also sometimes used at LZH. One particular patient, when interviewed in the exit survey, 
expressed his disappointment that he was not provided with free services though he presented an identification document from his VDC showing that he was poor. One disadvantage that was clearly identified to be the result of the lack of an SSU at LZH was that it created difficulty and inequality in identification of target groups. Also, the data of patients accessing free health care, and information on expenditure, was not properly maintained in the absence of an SSU.

It should be noted that, although there was no SSU at LZH, both hospitals received aid from the government for the expenses of free health-care services.

\section{DISCUSSION}

The results of this study show that the percentage of patients exempted from payment was $8.4 \%$ in WRH and $2.7 \%$ in LZH. A similar study by Basnet et al. in 2013 in a regional hospital in the midwestern region of Nepal showed that $10.8 \%$ of patients were exempted from payment. ${ }^{17}$ The percentage of patients receiving free services was very low at LZH and moderately low at WRH, although the population census report of 2011 showed the population of Rupandehi district to be much larger (880 196) than that of Kaski (492 098). ${ }^{19}$ The poor educational programme provided by the hospitals to inform the target groups on the availability of free health-care services contributed to the low number of patients receiving free services at $\mathrm{LZH}$.

This study found that the free services were utilized mostly by poor patients $(78.8 \%)$ and senior citizens $(10.5 \%)$ at WRH, Pokhara. The scenario was different at LZH, Butwal; the free services were utilized mostly by senior citizens $(82.4 \%)$, followed by poor patients $(12.3 \%)$, and this clearly shows that more poor patients were missed at LZH than at WRH. A survey done in 13 districts by RTI International and CARE Nepal in December 2009, to assess implementation of the free health-care policy, found that use of free services in primary health-care centres and district hospitals was more common in ultrapoor groups, followed by poor groups in all hospital departments: emergency, outpatient and inpatient. ${ }^{14}$ The reason for the difference in utilization of free services by different groups between our study and that of RTI International was that it was difficult for our research team to determine which group the clients belonged to, either ultrapoor or poor, based on the records maintained at the two hospitals.

People in the target groups were identified either by presentation of an identification card, or by the staff involved in treatment analysing the appearance of patients. At WRH, the card was the most common method for identification, although the staff assessment method was used in the absence of an identification card. At LZH, the staff assessment was the most common means of identifying patients in target groups, because this hospital lacked an SSU. Nevertheless, this policy does not distinguish between the poor and ultrapoor, and the government should produce a simple, clear and practical definition of target groups. ${ }^{21}$ A similar study by Basnet et al. in 2013 in a regional hospital of Surkhet district also did not differentiate between the poor and ultrapoor; that study showed that the poor used free health care in the highest numbers $(71.9 \%) .{ }^{17}$
The present study showed that most of the groups using the free services were upper-caste patients and poor patients, and also some nontarget groups. Similar to the present study, there are reports showing an increasing demand for free services because of unnecessary use of health care by nontarget groups, thus leading to a fall in the quality of the services and increasing health-care costs..$^{21,22}$ The upper-caste poor clients who utilized most of the free services in the present study had a good awareness of the access to free services, but the target groups from other marginalized caste groups, for whom the service is intended, had relatively poor knowledge of the free services; other studies have reported similar findings. ${ }^{21}$ One of the aims of the free service is to increase utilization of services by women; however, the present study showed almost equal numbers of males and females accessing services. The percentage of females using the free services was $50.6 \%$ at WRH and $47.9 \%$ at $\mathrm{LZH}$.

The study by Basnet et al. showed that $83.3 \%$ of patients using free services were from the geographical district where the hospital was situated, ${ }^{17}$ while the percentages in the present study were $51.8 \%$ for WRH and $56.4 \%$ for LZH. This shows that access to these hospitals is comparatively easier than access to the regional hospital in Surkhet for people from outside the geographical districts of WRH and LZH. One of the important factors indicating ease of access to a hospital is the number of people from rural areas utilizing the free services; in the present study WRH had a high percentage of referrals from rural areas at $66.4 \%$, while it was $35.6 \%$ at LZH.

Our research suffers from limitations such as insufficient sample size for qualitative research. Therefore, it gives preliminary findings only, and further research, including more interviews with staff and patients, is required to improve the current utilization of free health-care services in tertiarylevel hospitals by the target groups. This will help to identify the reasons for unintended use of free services, as well as to explore the reasons why poor and vulnerable people are not utilizing the free services to which they are entitled.

\section{Conclusion}

An important conclusion of this work is that there was very low access to and utilization of free health-care services in the two tertiary-care hospitals in western Nepal. This was mainly because the hospitals did not provide an adequate educational programme to inform the population about the availability of free health-care services, and also a lack of knowledge regarding free services and target groups among staff working in the hospitals. There was also unintended use of free healthcare services by nontarget groups, and this indicates the need for further simplification of the criteria used for identifying target groups. Based on the findings of this study, it is recommended that: (i) there are educational programmes for hospital staff to increase their awareness of the free health-care services, and inform them how to correctly identify target groups or how to help provide the free services to which target groups are entitled; (ii) hospitals initiate awareness/educational programmes to provide information about free health-care services to poor and marginalized caste groups; (iii) there are proper recording 
and reporting systems in place for the free health-care services, especially at LZH; (iv) an SSU is established at LZH to help poor and marginalized patients access the services; (v) the process of identifying target groups is simplified, as this could help to make free health-care services more easily available; and (vi) target groups have easy availability and accessibility of medicines and other services.

\section{REFERENCES}

1. Declaration of Alma-Ata. International Conference on Primary Health Care, Alma-Ata, 6-12 September. Geneva: World Health Organization; 1978 (who.int/publications/almaata_declaration_en.pdf, accessed 30 November 2015).

2. Hall JJ, Taylor R. Health for all beyond 2000: the demise of the AlmaAta Declaration and primary health care in developing countries. Med J Aust. 2003;178(1):17-20.

3. Ginneken W. Extending social security: policies for developing countries. Int Labour Rev. 2003;142(3):277-94.

4. Xu K, Evans DB, Carrin G, Aguilar-Rivera AM, Musgrove P, Evans T. Protecting households from catastrophic health spending. Health Aff (Millwood). 2007;26:972-83.

5. O’Donnell O, van Doorslaer E, Rannan-Eliya RP, Somanathan A, Adhikari SR, Akkazieva B et al. Who pays for health care in Asia? J Health Econ. 2008;27(2):460-75. doi:10.1016/j.jhealeco.2007.08.005.

6. Health financing for universal coverage and social health protection: bridging the health care divide. Kathmandu: WHO Technical Working Group on Health Care Financing; 2011 (http://p4h-network.net/ wp-content/uploads/2013/10/HFBackgroundPaper.pdf, accessed 30 November 2015)

7. Health systems financing: the path to universal health coverage. Geneva: World Health Organization; 2012 (http://www.who.int/health financing/ Health_Systems_Financing_Plan_Action.pdf, accessed 30 November 2015).

8. Striving for universal health coverage. Lancet. 2010;376(9755):1799. doi:10.1016/S0140-6736(10)62148-4.

9. Evans DB, Etienne C. Health systems financing and the path to universal coverage. Bull World Health Organ. 2010;88(6):402. doi:10.2471/ BLT.10.078741.

10. Nepal at the crossroads: setting the stage for improved social health protection: final report of a joint assessment of MoHP-GTZ. Kathmandu: Health Sector Support Programme; 2010 (http://p4h-network.net/wpcontent/uploads/2013/10/NepalSHPReport_finalprint.pdf, accessed 30 November 2015).

11. The Interim Constitution of Nepal 2063 (2007). Geneva: World Intellectual Property Organization; 2007 (http://www.wipo.int/wipolex/ en/text.jsp?file_id=189180, accessed 30 November 2015).
12. Annual report 2063/64 (2006/2007). Kathmandu: Department of Health Services, Government of Nepal; 2007 ( http://dohs.gov.np/sites/default/ files/1/files/Annual_Report_2063_64.pdf, accessed 30 November 2015).

13. Guideline for free essential health care services for poor and destitute people. Kathmandu: Ministry of Health and Population, Government of Nepal; 2006.

14. Nepal Health Sector Programme-II (NHSSP-II) 2010-2015. Kathmandu: Ministry of Health and Population, Government of Nepal; 2010 (nhssp. org.np/about/NHSSP 2 Policy Document.pdf, accessed 30 November 2015).

15. Ministry of Health and Population. A review of studies on Nepal's national free health care programme. Kathmandu: Ministry of Health and Population, Government of Nepal; 2013 (http://www.nhssp.org.np/ gesi/Free\%20health\%20services\%20\%28QA\%29\%202013_12_02.pdf, accessed 30 November 2015).

16. Assessing implementation of Nepal's free health care policy: third trimester health facility survey report. Kathmandu; Ministry of Health and Population, Government of Nepal; 2009 (https://www.rti.org/ pubs/31_nepal_assessingimplementation.pdf, accessed 30 November 2015).

17. Basnet R, Shrestha BR, Nagaraja S, Basnet B, Satyanarayana S, Zachariah R. Universal health coverage in a regional Nepali hospital: who is exempted from payment? Public Health Action. 2013;3(1):9092. doi:10.5588/pha.12.0082.

18. Regional annual review 2069-70. Pokhara; Western Regional Health Directorate, Ministry of Health and Population, Government of Nepal; 2013

19. Regional health profile. Pokhara: Western Regional Health Directorate, Ministry of Health and Population, Government of Nepal; 2013.

20. Social Service Unit establishment and operational guidelines 2069 (2012). Kathmandu: Ministry of Health and Population, Government of Nepal; 2012 (http://www.nhssp.org.np/gesi/SSU\%20guidelines.pdf, accessed 30 November 2015).

21. Implications of the Government of Nepal's free health care policy. NC, USA: RTI International; 2007.

22. Gurung R. Free health care policy in Nepal: recent trends and challenges. J Nepal Health Res Counc. 2009;7(15):138-9.

How to cite this article: Mahato PK, Paudel GS. Access to free health-care services for the poor in tertiary hospitals of western Nepal: a descriptive study. WHO South-East Asia J Public Health 2015; 4(2): 167-175.

Source of Support: Nil. Conflict of Interest: None declared. Contributorship: PM and GP designed and developed the research concept. PM collected and analysed the data and drafted the initial paper. GP reviewed the paper and made the necessary amendments. PM and GP agreed on the final version of the paper. 